\title{
The factor structure, reliability and validity of the Chinese version of the Van Dream Anxiety Scale
}

This article was published in the following Dove Press journal:

Neuropsychiatric Disease and Treatment

\author{
Xiang Wang' \\ Lisha Dai' \\ Meng Yin' \\ Yunlong Deng ${ }^{1,2}$ \\ 'Department of Clinical Psychology, \\ The Third Xiangya Hospital, Central \\ South University, Changsha, Hunan \\ 4I00I3, China; ${ }^{2}$ Psychosomatic Health \\ Institute, The Third Xiangya Hospital, \\ Central South University, Changsha, \\ Hunan 4I00I3, China
}

Background/purpose: Dream emotions and contents are associated with psychological well-being. Dream disturbances, such as frequent nightmares and dream anxiety, are associated with a variety of psychopathological conditions. Therefore, it is important to consider nightmares and the resulting dream anxiety. To address this issue, the Van Dream Anxiety Scale (VDAS) was designed especially for measuring nightmare frequency and dream anxiety caused by frightening dreams. As a Chinese version of VDAS may be helpful in promoting study of nightmare and dream anxiety among Chinese population, in the current study, we sought to develop a Chinese version of the VDAS (CVDAS).

Methods: We translated the VDAS into Chinese. To evaluate its validity and reliability, a sample of 1,081 Chinese college students from two universities answered the CVDAS, GAD-7, PHQ-9 and EPQ-R-N. Ninety of them answered the CVDAS twice. We also conducted exploratory factor analysis (EFA) to explore the structure of CVDAS.

Results: Excellent internal consistency (Cronbach's alpha coefficient was 0.926), split-half reliability (equal-length Spearman-Brown coefficient was 0.938 ) and good test-retest reliability (the intraclass correlation coefficient was 0.942 and $\mathrm{t}=-1.478, P=0.143$ ) of the CVDAS was presented. Exploratory factor analyses indicated a two-factor structure: sleep-related disturbances caused by nightmares and dysfunction caused by nightmares. Convergent and divergent validities were acceptable.

Conclusion: The CVDAS shows promise for the measurement of nightmare frequency and specific dream anxiety in Chinese population. Future study should confirm the reliability and validity in the clinical population and further improve this scale.

Keywords: nightmare, dream anxiety, assessment, Chinese population

\section{Introduction}

Sleep is a common biological feature of all mammal species including human beings and plays an important role in individual health. As one of the most attractive mental features of sleep, dreaming state is characterized by vivid, animated and bizarre experiences. ${ }^{1,2}$ The investigation of dream mechanisms and functions showed that rapid eye movement (REM) sleep is the brain state characterized with the most intense and delusive dream content, including the occurrence of bad dreams or nightmares. ${ }^{3-5}$ Previous studies showed that dreaming has many functions such as mood regulation, ${ }^{6}$ adaption, compensation, integration of new information into existing memory systems $\mathrm{s}^{7,8}$ and improvement of problem solving. ${ }^{9}$

The content of dreams is closely related to psychological well-being. ${ }^{10}$ Previous studies have indicated that the occurrence of recurrent dreams, nightmares and unpleasant daily dreams were related to one's mental health. ${ }^{1-13}$ On the one hand, positive emotion and content of dreams are associated with psychological well-being. ${ }^{8,14}$
Correspondence: Yunlong Deng Department of Psychiatry, The Third Xiangya Hospital, Central South University, Via No 138 Tongzipo Road, Yuelu District, Changsha 4I00I3, Hunan, China

Tel +8618975186178

Fax $+86731886 \mid 8487$

Email dylong@csu.edu.cn
Neuropsychiatric Disease and Treatment 2019:15 57-67

57

Dovepress f $y$ in $\mathbf{0}$

http:

(c) (1) (5) 2019 Wang et al. This work is published and licensed by Dove Medical Press Limited. The full terms of this license are available at https://www.dovepress.com/terms.php

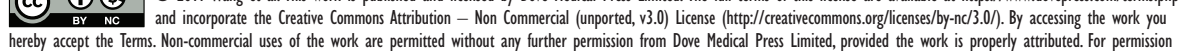
for commercial use of this work, please see paragraphs 4.2 and 5 of our Terms (https://www.dovepress.com/terms.php). 
A longitudinal study noted that when participants reported lower psychological well-being levels, their dreams were more inclined to contain aggressive, negative emotions, failures and misfortune rather than friendly interactions, positive emotions, successes and good fortune. ${ }^{14}$ On the other hand, dream disturbances, such as frequent nightmares and dream anxiety are associated with a variety of psychopathological conditions. ${ }^{15}$ Nightmares are defined as vivid, powerfully unpleasant or frightening dreams, containing intense negative emotions such as feelings of anxiety, fear, and threat, and can result in a startle awakening. ${ }^{16}$ Nightmares occur primarily during late night REM sleep and can result in many problems such as sleep disturbances and daytime dysfunction. Dream anxiety is waking anxiety caused by frightening dreams and is more predictive of psychological perturbations. ${ }^{17}$ Frequent nightmares are associated with psychopathology. Prior studies have shown that nightmares had significant clinical relevance and are associated with many mental disorders such as anxiety, ${ }^{13,18-20}$ depression, ${ }^{19,21}$ schizophrenia, ${ }^{22,23}$ dissociative disorders, ${ }^{24,25}$ borderline personality disorder, ${ }^{25,26}$ posttraumatic stress disorder, ${ }^{16,27}$ and even suicidal behavior. ${ }^{21,28,29}$ Kirov and Brand ${ }^{30}$ also pointed out that the occurrence of nightmares was related to increasing risks of developing psychiatric disorders in adolescence. Thus, it is clear that disturbing dreams are common in many different types of psychopathological conditions. In addition to nightmare frequency, nightmare distress was also a strong predictor of psychopathology score. ${ }^{11,31}$ Some evidence suggested that the association between nightmares and psychopathology might be largely regulated by an affection distress dispositional dimension rather than by nightmare frequency, particularly for psychological disorders marked by high level of negative affect (eg, anxiety and depression). However, the same relationship did not hold for psychopathology characterized by unusual cognitions (eg, dissociation and schizotypy). ${ }^{31}$ Nightmare frequency, more specifically, is associated with heightened anxiety about death, ${ }^{32}$ fear of annihilation, ${ }^{33}$ somatization, hostility, dissociation and schizophrenia-related psychopathology. ${ }^{19}$ A relationship between nightmare frequency and suicide risk was also observed. ${ }^{29}$ Therefore, relationships between nightmares and psychopathology may be measured by frequency measures as well as distress measures. In addition, there is also an association between nightmare frequency and some personality features such as schizoid and borderline personality, ${ }^{34}$ and neuroticism..$^{35}$

The incidence of nightmares is also important. Among the general population, $2 \%-6 \%$ of adults reported that they had frequent nightmares, and the percentage of people who reported at least one nightmare per month was 35\%-45\%. ${ }^{36-38}$ A nationwide survey conducted by Hublin et a ${ }^{39}$ noted that about $70 \%$ of adults reported occasional nightmares and $4 \%-8 \%$ reported frequent nightmares. Studies also reported that nightmares were most prevalent among children and adolescents. ${ }^{40,41}$

Therefore, it is important to be concerned about nightmares, and to promote the understanding of mental health and psychopathology. Unfortunately, the etiology and pathogenesis of nightmares are unclear, and there are no models that can adequately explain them. A chronic lack of research into the pathophysiological features of nightmares as well as a lack of valid measures to evaluate nightmares has hindered the development of nightmare research. Some meaningful attempts, however, provide directions. Levin and Nielsen ${ }^{31}$ proposed a nightmare model to explain the nightmare production process. This model was based on two global assumptions: cross-state continuity and multilevel explanation, which integrated explanatory concepts at neural level (a network of limbic and forebrain regions underlying emotion expression and representation) and a cognitive level (a dream production system that transforms fear memories into nightmare imagery). Although this model did not explain the pathology of nightmare satisfactorily, it provided great inspiration as a heuristic tool. Measuring nightmare frequency and dream anxiety with a standardized scale is crucial. There are few studies related to nightmares in China, most of which are qualitative studies. The lack of valid tools to assess nightmares also limits the development of nightmare research in China. Thus, an effective and Chinese culturebased nightmare assessment scale is urgently needed.

There are some scales to assess nightmare frequency and related indices, such as the 8-point Nightmare Frequency Scale, ${ }^{42}$ the Nightmare Frequency Questionnaire (NFQ) ${ }^{43}$ the Nightmare Effects Survey (NES), ${ }^{43}$ the Nightmare Distress Questionnaire (NDQ), ${ }^{44}$ and the Trauma-Related Nightmare Survey (TRNS ${ }^{45}$. However, these scales are either used to evaluate one single aspect of nightmares, or applied in a particular population, which limits the range of application. Most previous studies only measured nightmare frequency to explore the association between nightmare and psychopathology conditions, which is inadequate. Thus, a professional, elaborated scale measuring nightmare frequency and its effects was needed. Agargün et $\mathrm{al}^{7}$ provided a promising instrument tool, the Van Dream Anxiety Scale (VDAS), to measure nightmare frequency and its effects. The VDAS is an assessment instrument that can evaluate nightmare 
frequency and dream anxiety caused by frightening dreams and was developed by Agargün in 1999. The content of VDAS includes nightmare frequency, sleep problems resulting from nightmares, dream recall frequency, morning anxiety caused by nightmares, psychological problems, impairment of functioning, and autonomic symptoms, thus including most impacts of nightmares on health. The VDAS has shown good reliability and validity. The internal consistency reliability and test-retest reliability of the original version were 0.87 and 0.92 . In the validity study, the VDAS could distinguish between patients with nightmare disorder and healthy controls. It has turned out to be a valid and reliable instrument to measure nightmare frequency and dream anxiety. The VDAS was also widely used by numerous studies to assess dream anxiety and treatment response in subjects with nightmare. ${ }^{15,46,47}$ Due to cultural differences, especially the huge differences between Chinese culture and Western culture, it is unclear whether the VDAS can be a useful measurement of nightmare frequency and dream anxiety in China. Meanwhile, the structure of VDAS is not clear either, so the development of a Chinese version of the VDAS may be helpful in promoting the nightmare-related studies in the Chinese population and further promote the development and improvement of the scale. The aim of our study was first to translate the English version of VDAS into Chinese, and second to test the reliability and validity of the Chinese version in measuring dream anxiety among the Chinese population.

\section{Methods}

\section{Participants}

Participants were recruited from two universities in the Hunan Province in China by convenience sampling. We provided study information on the questionnaires and distributed it to students during a class break. After explaining the purpose and content of the study to the students, they agreed to participate and written informed consents were obtained. In the present study, 1,200 undergraduate students from 14 classes participated and 1,081 students fully completed questionnaires with no missing data. The effective return ratio was $90.1 \%$. In order to test the test-retest reliability, 90 students were randomly selected from three classes to complete the CVDAS again after a week and 87 valid questionnaires were collected. The effective return ratio was $96.7 \%$. Information about age and gender was obtained from all participants. The research protocol was approved by the local ethics committee. The study was conducted in accordance with the Declaration of Helsinki.

\section{Measures}

\section{The Chinese version of VDAS}

The original VDAS consists of 17 items for assessing nightmare frequency and dream anxiety caused by frightening dreams. Four items (items 7-10) are used to collect clinical information but are not tabulated in the scoring of VDAS; the remaining 12 items are rated on a 5-point Likert scale ranging from 0 (never) to 4 (often) and are concerned with nightmare frequency, difficulty in falling asleep after a nightmare, fear of sleeping because of anticipated nightmare, trouble sleeping, dream recall frequency, sleepiness, daytime anxiety, occupational distress, familial distress, social distress, psychological disturbances, and memory/ concentration problems. Item 5 is related to autonomic hyperactivity and consists of 12 symptoms. Each of the 12 symptoms is also rated on a $0-4$ scale. If the total score obtained by adding the 12 symptom scores is between 0 and 10 , the sum score of this item is 0 ; for $11-20$ it is 1 ; for $21-30$ it is 2 ; for $31-40$ it is 3 ; and for $41-48$ it is 4 . Thus, the 13-item scores are summed to yield a global VDAS score of $0-52 .^{7}$ We obtained permission to use the VDAS from Agargün who was the original author of VDAS. First, two psychological researchers translated the English version of VDAS into Chinese. Then, the translation was examined by two psychological professors for surface-level relevance to the construct of interest and whether each item was suitable for the Chinese population. Next, the back-translation of the Chinese version of the items was performed by a professional bilingual translator who had not read the original version of VDAS. The back-translated version was reviewed and modified by the author of the VDAS until it accurately expressed the same meaning as the original version. Participants reported no misunderstanding of Chinese version after conducting a pilot test. The original and Chinese version of VDAS are presented in Supplementary material.

\section{Generalized Anxiety Disorder - 7 Questionnaire (GAD-7)}

GAD-7, developed by Spitzer et al, ${ }^{48}$ is a 7 -item self-reported scale used to measure the severity of generalized anxiety disorders (GAD). Each item of the GAD-7 is weighted on a 0-3 scale, with the total score ranging from 0 to 21 . Scores of 5-9, 10-14, and $\geq 15$ indicate mild, moderate, and severe anxiety, respectively. GAD-7 has been translated into many languages and exhibits excellent internal consistency in different versions (Cronbach's $\alpha$ between 0.89 and 0.92). ${ }^{48-51}$ The Chinese version of GAD-7 shows good reliability and validity. ${ }^{51}$ The Cronbach's $\alpha$ was found to be 0.898 and 
the test-retest reliability was 0.856 . Using 10 as cutoff, the sensitivity and specificity of GAD-7 were $86.2 \%$ and $95.5 \%$, respectively. Thus, we use the Chinese version of GAD-7 to assess the severity of anxiety for evaluating convergent and divergent validity.

\section{Patient health questionnaire-9 (PHQ-9)}

PHQ-9 consists of nine items evaluating and monitoring depression severity and was developed by Spitzer et al. ${ }^{52}$ Items of the PHQ-9 are also rated on a 4-point Likert scale, ranging from 0 (never) to 3 (nearly every day), with a summed score ranging from 0 to 27 . Scores of 5-9, 10-14, 15-19, and $\geq 20$ indicate mild, moderate, moderately severe, and severe depression, respectively. The scale is shown to have high internal consistency (Cronbach's $\alpha$ between 0.86 and $0.89)^{53}$ and high test-retest reliability (Cronbach's $\alpha$ between 0.84 and 0.95$).{ }^{53,54}$ The PHQ-9 has also been translated into several languages, including Swedish, ${ }^{55}$ Thai, ${ }^{56}$ Greek,,${ }^{57}$ and Chinese. ${ }^{58}$

The Chinese version of PHQ-9 had good internal consistency reliability (Cronbach's $\alpha=0.86$ ) and test-retest reliability (Cronbach's $\alpha=0.86) .{ }^{58}$ A cutoff score of 7 or higher on the PHQ-9 had a sensitivity of $86 \%$ and specificity of $86 \%$. Thus, the Chinese version of PHQ-9 is a valid and efficient tool for screening depression. In this study, we use PHQ-9 to assess convergent validity and divergent validity.

\section{Neuroticism scale of the Eysenck Personality Questionnaire-Revised: Short Form (EPQ-R-N)}

As a well-advocated personality assessment instrument, EPQ-R contains 100 items, and Eysenck et al ${ }^{59}$ revised a new version consisting of 48 items. Like the original version, the Chinese version of EPQ-R involves 4 subscales with 48 items. " 60 "Yes" or "No" serve as response to each item with score 1 or 0 . Cronbach's alpha coefficient of this subscale was 0.818 . In this study, the neuroticism subscale was only adopted to test convergent validity.

\section{Data analysis}

Item analysis and reliability

Item-total statistics were used for testing the homogeneity of this scale, estimating the corrected item-total correlations, which should be above $0.3 .^{61}$ The item-total statistics was generated for each of 13 items. Internal consistency, split-half reliability, and test-retest reliability were used to evaluate the reliability of the CVDAS. Internal consistency was assessed by Cronbach's alpha coefficient.
The Spearman-Brown coefficient was used for the evaluation of split-half reliability, for which we divided the items which were scored separately into equal parts by odd-even grouping method (we eliminate item 5 because it is not scored directly). For the test-retest reliability, the intraclass correlation coefficient (ICC) and paired $t$-test were used. The ICC was considered to be more suitable compared to Pearson's correlation coefficients. ${ }^{62}$

\section{Validity}

Factor analysis was carried out to explore the structure of the CVDAS. We conducted exploratory factor analysis (EFA) in order to identify the latent variables. The Kaiser-MeyerOlkin and Bartlett's test of sphericity were performed for the purpose of testing the application condition of factor analysis. The EFA was performed by principal axis factoring (PAF) and Promax rotation. Meanwhile, we also inspected the results of eigenvalues and scree plot. The EFA was conducted by SPSS 24.0. For the convergent validity, correlation analysis was performed between CVDAS and GAD-7, PHQ-9 and EPQ-R-N. Pearson's correlation coefficient was used to evaluate the convergent validity. For the divergent validity, one-way ANOVA examined the differences in the CVDAS scores among participants with different severity of anxiety and depression. A $P$-value less than 0.05 was considered as statistically significant.

\section{Results}

\section{Descriptive statistics of study subjects}

For all 1,081 participants, questionnaires were complete with no missing data. The distribution of each item was close to normality. All the items fell within the recommended range reflecting skew and kurtosis coefficients, which should not be above 3 and 10 separately. ${ }^{63}$ As shown in Table 1, the floor effect for the VDAS was $29 \%$, indicating moderate floor effect. ${ }^{64}$ The observed ceiling effect was negligible with the percentage of $0.3 \%$. Participants were 546 men $(50.5 \%)$ and 535 women $(49.5 \%)$. The mean age was $19.83 \pm 0.92$ (mean $\pm \mathrm{SD}$ ) years, ranging from 17 to 24 . We performed independent samples $t$-test between genders and found that there were significant differences on the scores of CVDAS ( $\mathrm{t}=-3.749, P<0.01)$; that is, females were significantly higher than males in dream anxiety. Mean and SD for age and each questionnaire are presented in Table 1.

\section{Item analysis and reliability}

Item-total statistics were used to test the homogeneity of the CVDAS. The result showed that all of the corrected 
Table I Descriptive statistics for age and measurements

\begin{tabular}{|c|c|c|c|c|c|c|c|}
\hline & $\mathbf{N}$ & Mean (SD) & Min & Max & $95 \% \mathrm{Cl}$ & $\% \min$ & $\% \max$ \\
\hline Age (years) & $|, 08|$ & $19.83(0.92)$ & 17 & 24 & & & \\
\hline CVDAS & $|, 08|$ & $5.16(6.22)$ & 0 & 31 & $4.97-5.35$ & 29 & 0.3 \\
\hline Male & 546 & $4.46(6.18)$ & 0 & 29 & $4.19-4.73$ & 36.4 & 0.2 \\
\hline Female & 535 & $5.87(6.16)$ & 0 & 31 & $5.60-6.14$ & 21.3 & 0.6 \\
\hline CVDAS-R & 87 & 3.10 (4.29) & 0 & 20 & $2.64-3.56$ & 40.2 & I.I \\
\hline GAD-7 & $\mathrm{I}, 08 \mathrm{I}$ & $3.28(3.48)$ & 0 & 21 & $3.17-3.39$ & 26.9 & 0.3 \\
\hline PHQ-9 & $|, 08|$ & $4.56(4.28)$ & 0 & 27 & $4.43-4.69$ & 16.9 & 0.1 \\
\hline EPQ-R-N & $|, 08|$ & 47.35 (II.47) & 33.69 & 74.37 & $47.0-47.7$ & 8.1 & 0.8 \\
\hline
\end{tabular}

Abbreviations: CVDAS, the Van Dream Anxiety Scale; CVDAS-R, the Van Dream Anxiety Scale at second time; EPQ-R-N, Neuroticism subscale of the Eysenck Personality Questionnaire-Revised: Short Form; GAD-7, Generalized Anxiety Disorder - 7 Questionnaire; PHQ-9, Patient Health Questionnaire-9.

item-total correlations above the recommended cutoff value of 0.3 ranged from 0.541 to $0.743 .{ }^{61}$ Internal consistency was evaluated with Cronbach's alpha coefficient, which was regarded as unacceptable if it was below 0.6 or $0.5 .{ }^{65}$ This index of CVDAS score was 0.926 , which indicates excellent internal consistency. The Cronbach's alphas with each item deleted were all less than 0.926 . The split-half reliability was tested by Spearman-Brown coefficient, which showed that equal-length Spearman-Brown coefficient was 0.938. The test-retest reliability was tested by ICC and paired $t$-test. Based on the recommendation of a 1998 study, ${ }^{66}$ an ICC $\leq 0.1$ was considered to be no consistency, $0.11-0.40$ was poor, 0.4-0.6 was ordinary, $0.61-0.80$ was moderate, and $>0.8$ was good. The results showed that ICC was 0.942 for CVDAS $(P<0.01)$ and the value of $t$ was $-1.478(P=0.143)$, indicating a good test-retest reliability and stability for the CVDAS. ${ }^{66}$

\section{Factor structure}

The EFA was performed on total scores of CVDAS from the total sample $(n=1,081)$. The significance of Bartlett's test of sphericity was observed $\left(\chi^{2}=8,880.11, P<0.001\right)$. The KMO value was 0.93 , which was considered perfect. ${ }^{67}$ These results indicated that our data were appropriate for factor analysis. The inspection of the scree plot and eigenvalues showed two factors in this analysis, which accounted for $64.19 \%$ of the total variance. Moreover, factor loadings were all above the 0.4 cutoff criterion. As shown in Table 2, there were five items which loaded highly on factor 1 , and eight items loaded highly on factor 2 . The loading of each item on its factor ranged from acceptable to good. ${ }^{68}$ This is the first time to conduct EFA for VDAS. According to the EFA result, the content of the first factor was focused on sleep disturbances caused by nightmares so was labeled sleep-related disturbances caused by nightmares (SDs). The second factor focused on dysfunction caused by nightmares and was labeled dysfunction caused by nightmares (Dys).
These two factors were found to be correlated significantly, $r=0.67, P<0.01$. This result was consistent with the theoretical basis that nightmares not only could deteriorate sleep quality by frequent nocturnal awakenings, fear of falling asleep or difficulties of returning to sleep, ${ }^{69}$ but also resulted in impairment in social, occupational, and other important areas of functioning. ${ }^{16,70}$ Therefore, it is reasonable to classify the CVDAS as these two dimensions.

\section{Convergent and divergent validity}

As presented in Table 3, the score of the CVDAS showed a significant positive correlation with GAD-7 $(r=0.502$, $P<0.01)$, PHQ-9 $(r=0.487, P<0.01)$, and EPQ-R-N $(r=0.432, P<0.01)$, which measured the severity of generalized anxiety and depression, and neuroticism. These results

Table 2 Exploratory factor analysis pattern matrix and structure matrix rotated to the Promax criterion using principal axis factoring $(n=I, 08 I)$

\begin{tabular}{|l|l|l|l|l|}
\hline \multirow{2}{*}{ Items } & \multicolumn{2}{|l|}{ Pattern matrix } & \multicolumn{2}{l|}{ Structure matrix } \\
\cline { 2 - 5 } & Factor I & Factor $\mathbf{2}$ & Factor I & Factor $\mathbf{2}$ \\
\hline I. NF & $\mathbf{0 . 7 8 9}$ & -0.053 & $\mathbf{0 . 7 5 5}$ & 0.459 \\
2. DFA & $\mathbf{0 . 7 5 2}$ & 0.048 & $\mathbf{0 . 7 8 3}$ & 0.536 \\
3. SF & $\mathbf{0 . 6 8 4}$ & 0.090 & $\mathbf{0 . 7 4 2}$ & 0.534 \\
4. TS & $\mathbf{0 . 8 4 I}$ & -0.064 & $\mathbf{0 . 7 9 9}$ & 0.482 \\
5. AH & 0.252 & $\mathbf{0 . 4 6 5}$ & 0.554 & $\mathbf{0 . 6 2 9}$ \\
6. DRF & $\mathbf{0 . 4 3 7}$ & 0.178 & $\mathbf{0 . 5 5 3}$ & 0.462 \\
II. SL & 0.326 & $\mathbf{0 . 4 4 9}$ & 0.617 & $\mathbf{0 . 6 6 0}$ \\
I2. MA & 0.259 & $\mathbf{0 . 5 7 8}$ & 0.634 & $\mathbf{0 . 7 4 6}$ \\
I3. OD & -0.065 & $\mathbf{0 . 8 9 9}$ & 0.518 & $\mathbf{0 . 8 5 7}$ \\
I4. FD & -0.089 & $\mathbf{0 . 8 5 4}$ & 0.466 & $\mathbf{0 . 7 9 7}$ \\
I5. SoD & -0.110 & $\mathbf{0 . 9 2 9}$ & 0.493 & $\mathbf{0 . 8 5 7}$ \\
I6. PD & 0.127 & $\mathbf{0 . 6 8 5}$ & 0.571 & $\mathbf{0 . 7 6 7}$ \\
I7. M/C & 0.099 & $\mathbf{0 . 7 1 9}$ & 0.566 & $\mathbf{0 . 7 8 4}$ \\
\hline
\end{tabular}

Notes: Bold data indicates which factor the items belong to.

Abbreviations: $\mathrm{AH}$, related to autonomic hyperactivity; DFA, difficulty in falling asleep after nightmare; DRF, dream recall frequency; FD, familial distress; M/C, memory/concentration problems; MA, morning anxiety; NF, nightmare frequency; OD, occupational distress; PD, psychological disturbances; SoD, social distress; SF, sleeping fear because of nightmare; SL, sleepiness; TS, trouble sleeping. 
Table 3 Inter-correlations between scales

\begin{tabular}{|l|l|l|l|l|l|}
\hline & $\mathbf{1}$ & $\mathbf{2}$ & $\mathbf{3}$ & $\mathbf{4}$ & $\mathbf{5}$ \\
\hline I. CVDAS & & & & & \\
2. SDs & $0.889^{* *}$ & & & & \\
3. Dys & $0.936^{* *}$ & $0.670^{* *}$ & & & \\
4. GAD-7 & $0.502^{* *}$ & $0.448^{* *}$ & $0.468^{* *}$ & & \\
5. PHQ-9 & $0.487^{* *}$ & $0.420^{* *}$ & $0.465^{* *}$ & $0.718^{* *}$ & \\
6. EPQ-R-N & $0.432^{* *}$ & $0.399^{* *}$ & $0.394^{* *}$ & $0.633^{* *}$ & $0.642^{* *}$ \\
\hline
\end{tabular}

Notes: Data presented as Pearson's correlation coefficient $(r)$. **Means $P<0.01$ (two-tailed).

Abbreviations: CVDAS, the Van Dream Anxiety Scale; Dys, dysfunction caused by nightmares; EPQ-R-N, Neuroticism subscale of the Eysenck Personality Questionnaire-Revised: Short Form; GAD-7, Generalized Anxiety Disorder 7-items scale; PHQ-9, Patient Health Questionnaire-9; SDs, sleep-related disturbances caused by nightmares.

supported the convergent validity of CVDAS. To examine the divergent validity, we conducted one-way ANOVA and multiple comparison to examine differences in the CVDAS scores among participants with different severity of anxiety and depression. The results of one-way ANOVA and multiple comparison are presented in Table 4. We combined participants with moderate and severe anxiety due to the small number of people with severe anxiety. Similarly, we also combined people with moderately severe and severe depression. These results indicated that there were significant differences among people with different anxiety and depression severity in scores of CVDAS and the CVDAS can effectively reflect different levels of dream anxiety among different people. These results also supported the divergent validity of CVDAS.

\section{Discussion}

The present study developed the Chinese version of the VDAS and examined psychometric properties of this scale in a Chinese sample of more than 1,000 college students in order to provide a better instrument to measure the nightmare frequency and dream anxiety in mainland China. Psychometric properties, including reliability and validity, were tested in the total sample. The CVDAS showed an excellent reliability with a Cronbach's alpha coefficient of 0.926 obtained for the scale indicating a high degree of internal homogeneity. ${ }^{71}$ Split-half reliability is also good with the equal-length Spearman-Brown coefficient of 0.938. Equally, good stability was also confirmed by its test-retest reliability, estimated by ICC and a paired $t$-test (ICCs $=0.942, P<0.01$; $\mathrm{t}=-1.478, P=0.143)$. We conducted EFA for the CVDAS for the first time and the results indicated that CVDAS had two factors: sleep-related disturbances caused by nightmares (SDs) (items 1-4 and 6) and dysfunction caused by nightmares (Dys) (items 5 and 11-17). This result was inconsistent with previous theoretical basis. Item 6 focusing on dream recall frequency was loaded on SDs, which was not a surprise and there were some explanations. The occurrence of sleep-related disturbances, such as difficulty in falling asleep after nightmare (item 2), and sleep fear because of nightmare (item 3), is because the dreamer can recall the nightmare in detail after awakening from nightmare. Thus, it seems reasonable to classify item 6 into SDs. Item 5 is related to autonomic hyperactivity, which consists of 12 symptoms

Table 4 One-way ANOVA and post-hoc tests among participant with different severity of anxiety and depression

\begin{tabular}{|c|c|c|c|c|c|}
\hline \multirow{2}{*}{$\begin{array}{l}\text { Dependent variable: } \\
\text { VDAS score }\end{array}$} & \multirow[t]{2}{*}{ Mean difference } & \multirow[t]{2}{*}{ Standard error } & \multirow[t]{2}{*}{ Significance } & \multicolumn{2}{|l|}{$95 \% \mathrm{Cl}$} \\
\hline & & & & Lower & Upper \\
\hline \multirow{2}{*}{\multicolumn{6}{|c|}{$\begin{array}{l}\text { Severity of anxiety } \\
\text { No }\end{array}$}} \\
\hline & & & & & \\
\hline Mild & $-5.15^{*}$ & 0.55 & 0.000 & -6.48 & -3.82 \\
\hline Moderate to severe & $-11.78 *$ & 1.29 & 0.000 & -14.95 & -8.59 \\
\hline \multicolumn{6}{|l|}{ Mild } \\
\hline Moderate to severe & $-6.62 *$ & 1.38 & 0.000 & -10.01 & -3.24 \\
\hline \multicolumn{6}{|l|}{ Severity of depression } \\
\hline \multicolumn{6}{|l|}{ No } \\
\hline Mild & $-3.17^{*}$ & 0.38 & 0.000 & -4.18 & -2.16 \\
\hline Moderate & $-7.55^{*}$ & 0.91 & 0.000 & -10.00 & -5.11 \\
\hline Moderately severe to severe & $-11.44 *$ & 1.53 & 0.000 & -15.72 & -7.17 \\
\hline \multicolumn{6}{|l|}{ Mild } \\
\hline Moderate & $-4.38^{*}$ & 0.96 & 0.000 & -6.94 & -1.81 \\
\hline Moderately severe to severe & $-8.27^{*}$ & 1.56 & 0.000 & -12.61 & -3.93 \\
\hline Moderate & & & & & \\
\hline Moderately severe to severe & -3.89 & 1.77 & 0.175 & -8.70 & 0.92 \\
\hline
\end{tabular}

Notes: $* P<0.05$; bold data indicate significant differences.

Abbreviation: VDAS, Van Dream Anxiety Scale. 
including shortness of breath, dizziness, exhaustion, palpitation, sweating, shivering, nausea, having stomach ache, tightness in chest, dry mouth, fear of death, and sore throat. These symptoms also belong to dysfunction. Therefore, item 5 loaded on Dys is also reasonable. The analysis of the structure of VDAS will help us to better understand the effects of nightmares and provide a guidance for further assessments and interventions. Moreover, good convergence was confirmed by correlations between CVDAS score, GAD-7 score, PHQ-9 score and the EPQ-R-N. As expected, the total scores of CVDAS were positively correlated with the GAD-7 score, PHQ-9 score and EPQ-R-N. In addition, we also explored the inter-correlation between nightmare frequency (item 1) with GAD-7 and PHQ-9, finding that nightmare frequency had significant positive correlation with GAD-7 $(r=0.345, P<0.01)$ and PHQ-9 $(r=0.298, P<0.01)$. This result also supported the fact mentioned above that the association between nightmares and psychopathology should consider both frequency measures and distress measures. For the divergent validity, we conducted one-way ANOVA and multiple comparison to examine differences in the CVDAS scores among participants with different severity of anxiety and depression. The results showed that the CVDAS could effectively reflect different levels of dream anxiety among different people, indicating good divergent validity. This result was in line with findings from previous studies. ${ }^{7,72}$

Overall, our findings supported that the CVDAS had sufficient stability and reliability, as well as validity for assessment of dream anxiety. The CVDAS primarily intended to measure dream anxiety but not provide accurate clinical diagnoses, which was similar to the Pittsburgh Sleep Quality Index (PSQI). ${ }^{73}$ The CVDAS could be used in epidemiological studies to examine patients with dream anxiety. Moreover, the CVDAS could also provide a longitudinal assessment of dream anxiety and treatment response in subjects with nightmares.

\section{Advantages and limitations}

Our study has several strengths. Firstly, we translated the VDAS into Chinese and tested its reliability and validity in a Chinese population, providing a valid instrument tool for nightmare research in China. This is the first step to promote the development of nightmare research in China. Secondly, we conducted EFA for the first time, which defined the factor structure of VDAS. The result of EFA indicated that VDAS had been classified into two dimensions: sleep-related disturbances caused by nightmares (SDs) and dysfunction caused by nightmares (Dys), which can help us understand the effects of nightmares better and provide a guidance for further assessments and interventions. This work also improved the research on this scale itself. Thirdly, to some extent, our study has good credibility and generality because of large sample size $(n=1,081)$, unlike previous studies which mostly used less than $100 .^{7,72}$

There are certain limitations to the current study. Firstly, the participants were only recruited from university students by convenience sampling and they were mostly healthy people. Consequently, they were predominantly young without nightmare disorder. Clinical samples are needed to establish the generalizability of this measurement. Secondly, we were unable to diagnose whether the participants had nightmare disorder due to limited condition, since the cutoff point of this scale had not been calculated, as well as specificity and sensitivity. Further study should supplement the cutoff point of this scale. Finally, we were unable to examine the responsiveness to clinical changes of this measure; this should be explored further in the future.

\section{Conclusion}

Sufficient reliability and validity of CVDAS were confirmed in a Chinese college student sample. More important, this study provided a valid instrument to measure nightmare frequency and dream anxiety and laid a solid foundation for future research on nightmares in China. Our study also conducted EFA for the first time and defined the factor structure of CVDAS, which further perfected the scale and provided a guidance for future studies. This study showed that the CVDAS was well accepted, easy to fill out and not timeconsuming. In sum, the CVDAS will be a promising tool to assess nightmare frequency and dream anxiety in China, and to enhance understanding of the link between nightmares with psychopathology. Future study should confirm the reliability and validity in clinical population and further improve this scale, for example, supplementing the cutoff point.

\section{Ethical approval}

The Institutional Review Board (IRB) of the Third Xiangya Hospital in Hunan approved the study (2018-S370).

\section{Acknowledgments}

We would like to thank Ms. Wu Yan for her help in data collection and the college students for completion of the questionnaires. This research was supported by the New Xiangya Talent Project of the Third Xiangya Hospital of Central South University (grant no 20150302). 


\section{Disclosure}

The authors report no conflicts of interest in this work.

\section{References}

1. Hobson JA. How the brain goes out of its mind. Endeavour. 1996;20(2):86-89.

2. Hobson JA. REM sleep and dreaming: towards a theory of protoconsciousness. Nat Rev Neurosci. 2009;10(11):803-813.

3. Hobson JA, Pace-Schott EF, Stickgold R. Dreaming and the brain: toward a cognitive neuroscience of conscious states. Behav Brain Sci. 2000;23(6):793-842.

4. Fosse R, Stickgold R, Hobson JA. Thinking and hallucinating: reciprocal changes in sleep. Psychophysiology. 2004;41(2):298-305.

5. McNamara P, Johnson P, McLaren D, Harris E, Beauharnais C, Auerbach S. REM and NREM sleep mentation. Int Rev Neurobiol. 2010;92:69-86.

6. Hartmann E. Outline for a theory on the nature and functions of dreaming. Dreaming. 1996;6(2):147-170.

7. Agargun MY, Kara H, Bilici M, et al. The van dream anxiety scale-A subjective measure of dream anxiety in nightmare sufferers. Sleep Hypn. 1999;4:204-211.

8. Bódizs R, Simor P, Csóka S, Bérdi M, Kopp MS. Dreaming and health promotion: A theoretical proposal and some epidemiological establishments. Eur J Ment Health. 2008;3(1):35-62.

9. Cartwright R. The contribution of the psychology of sleep and dreaming to understanding sleep-disordered patients. Sleep Med Clin. 2008; 3(2):157-166.

10. Brand S, Beck J, Kalak N, et al. Dream recall and its relationship to sleep, perceived stress, and creativity among adolescents. J Adolesc Health. 2011;49(5):525-531.

11. Blagrove M, Farmer L, Williams E. The relationship of nightmare frequency and nightmare distress to well-being. J Sleep Res. 2004; 13(2):129-136.

12. Brown RJ, Donderi DC. Dream content and self-reported well-being among recurrent dreamers, past-recurrent dreamers, and nonrecurrent dreamers. J Pers Soc Psychol. 1986;50(3):612-623.

13. Zadra A, Donderi DC. Nightmares and bad dreams: their prevalence and relationship to well-being. J Abnorm Psychol. 2000;109(2):273-281.

14. Pesant N, Zadra A. Dream content and psychological well-being: a longitudinal study of the continuity hypothesis. J Clin Psychol. 2006; 62(1):111-121.

15. Simor P, Köteles F, Sándor P, Petke Z, Bódizs R. Mindfulness and dream quality: the inverse relationship between mindfulness and negative dream affect. Scand J Psychol. 2011;52(4):369-375.

16. American Psychiatric Association. Diagnostic and Statistical Manual of Mental Disorders: DSM-V. 5th ed. Washington, DC: American Psychiatric Association; 2013.

17. Miró E, Martínez MP. Affective and personality characteristics in function of nightmare prevalence, nightmare distress, and interference due to nightmares. Dreaming. 2005;15(2):89-105.

18. Haynes SN, Mooney DK. Nightmares: etiological, theoretical, and behavioral treatment considerations. Psychol Rec. 1975;25(2):225-236.

19. Levin R, Fireman G. Nightmare prevalence, nightmare distress, and self-reported psychological disturbance. Sleep. 2002;25(2):205-212.

20. Nielsen TA, Laberge L, Paquet J, Tremblay RE, Vitaro F, Montplaisir J. Development of disturbing dreams during adolescence and their relation to anxiety symptoms. Sleep. 2000;23(6):727-736.

21. Nadorff MR, Nazem S, Fiske A. Insomnia symptoms, nightmares, and suicidal ideation in a college student sample. Sleep. 2011;34(1):93-98.

22. Mume CO. Nightmare in schizophrenic and depressed patients. Eur J Psychiatry. 2009;23(3):177-183.

23. Hartmann E, Russ D, van der Kolk B, Falke R, Oldfield M. A preliminary study of the personality of the nightmare sufferer: relationship to schizophrenia and creativity? Am J Psychiatry. 1981;138(6):794-797.
24. Agargun MY, Kara H, Ozer OA, Selvi Y, Kiran U, Ozer B. Clinical importance of nightmare disorder in patients with dissociative disorders. Psychiatry Clin Neurosci. 2003;57(6):575-579.

25. Semiz UB, Basoglu C, Ebrinc S, Cetin M. Nightmare disorder, dream anxiety, and subjective sleep quality in patients with borderline personality disorder. Psychiatry Clin Neurosci. 2008;62(1):48-55.

26. Simor P, Csóka S, Bódizs R. Nightmares and bad dreams in patients with borderline personality disorder: fantasy as a coping skill? Eur $J$ Psychiatry. 2010;24(1):28-37.

27. Nemeroff CB, Bremner JD, Foa EB, Mayberg HS, North CS, Stein MB. Posttraumatic stress disorder: a state-of-the-science review. J Psychiatr Res. 2006;40(1):1-21

28. Sjöström N, Hetta J, Waern M. Persistent nightmares are associated with repeat suicide attempt: a prospective study. Psychiatry Res. 2009; 170(2-3):208-211.

29. Tanskanen A, Tuomilehto J, Viinamäki H, Vartiainen E, Lehtonen J, Puska P. Nightmares as predictors of suicide. Sleep. 2001;24(7): 844-847.

30. Kirov R, Brand S. Nightmares as predictors of psychiatric disorders in adolescence. Curr Trends Neurol. 2011;5:1-12.

31. Levin R, Nielsen TA. Disturbed dreaming, posttraumatic stress disorder, and affect distress: a review and neurocognitive model. Psychol Bull. 2007;133(3):482-528.

32. Dunn KK, Barrett D. Characteristics of nightmare subjects and their nightmares. Psychiatr J Univ Ott. 1988;13(2):91-93.

33. Levin R, Hurvich MS. Nightmares and annihilation anxiety. Psychoanalytic Psychology. 1995;12(2):247-258.

34. Levin R, Raulin ML. Preliminary evidence for the proposed relationship between frequent nightmares and schizotypal symptomatology. J Pers Disord. 1991;5(1):8-14.

35. Roberts J, Lennings CJ. Personality, psychopathology and nightmares in young people. Pers Individ Dif. 2006;41(4):733-744.

36. Sandman N, Valli K, Kronholm E, et al. Nightmares: prevalence among the finnish general adult population and war veterans during 1972-2007. Sleep. 2013;36(7):1041-1050.

37. Li SX, Zhang B, Li AM, Wing YK. Prevalence and correlates of frequent nightmares: a community-based 2-phase study. Sleep. 2010; 33(6):774-780

38. Schredl M. Nightmare frequency and nightmare topics in a representative German sample. Eur Arch Psychiatry Clin Neurosci. 2010;260(8): 565-570.

39. Hublin C, Kaprio J, Partinen M, Koskenvuo M. Nightmares: familial aggregation and association with psychiatric disorders in a nationwide twin cohort. Am J Med Genet. 1999;88(4):329-336.

40. Li SX, Yu MW, Lam SP, et al. Frequent nightmares in children: familial aggregation and associations with parent-reported behavioral and mood problems. Sleep. 2011;34(4):487-493.

41. Munezawa T, Kaneita Y, Osaki Y, et al. Nightmare and sleep paralysis among Japanese adolescents: a nationwide representative survey. Sleep Med. 2011;12(1):56-64.

42. Schredl M, Gilles M, Wolf I, et al. Nightmare frequency in last trimester of pregnancy. BMC Pregnancy Childbirth. 2016;16(1):346.

43. Krakow B, Hollifield M, Schrader R, et al. A controlled study of imagery rehearsal for chronic nightmares in sexual assault survivors with PTSD: a preliminary report. J Trauma Stress. 2000;13(4): 589-609.

44. Belicki K. The relationship of nightmare frequency to nightmare suffering with implications for treatment and research. Dreaming. 1992b;2(3):143-148.

45. Cranston CC, Miller KE, Davis JL, Rhudy JL. Preliminary validation of a brief measure of the frequency and severity of nightmares: The Trauma-Related Nightmare Survey. J Trauma Dissociation. 2017; 18(1):88-99.

46. Selvi Y, Aydin A, Gumrukcuoglu HA, et al. Dream anxiety is an emotional trigger for acute myocardial infarction. Psychosomatics. 2011; 52(6):544-549 
47. Ozdemir PG, Karadag AS, Selvi Y, et al. Assessment of the effects of antihistamine drugs on mood, sleep quality, sleepiness, and dream anxiety. Int J Psychiatry Clin Pract. 2014;18(3):161-168.

48. Spitzer RL, Kroenke K, Williams JB, Löwe B. A brief measure for assessing generalized anxiety disorder: the GAD-7. Arch Intern Med. 2006;166(10):1092-1097.

49. Löwe B, Decker O, Müller S, et al. Validation and standardization of the Generalized Anxiety Disorder Screener (GAD-7) in the general population. Med Care. 2008;46(3):266-274.

50. Kertz S, Bigda-Peyton J, Bjorgvinsson T. Validity of the Generalized Anxiety Disorder-7 scale in an acute psychiatric sample. Clin Psychol Psychother. 2013;20(5):456-464.

51. He XY, Li CB, Qian J, Cui HS, Wu WY. Reliability and validity of a generalized anxiety disorder scale in general hospital outpatients Shanghai Arch Psychiatry. 2010;22(4):200-203. Chinese.

52. Spitzer RL, Kroenke K, Williams JB. Validation and utility of a selfreport version of PRIME-MD: the PHQ primary care study. Primary care evaluation of mental disorders. Patient health questionnaire. JAMA. 1999;282(18):1737-1744.

53. Kroenke K, Spitzer RL, Williams JB. The PHQ-9: validity of a brief depression severity measure. J Gen Intern Med. 2001;16(9):606-613.

54. Löwe B, Spitzer RL, Gräfe K, et al. Comparative validity of three screening questionnaires for DSM-IV depressive disorders and physicians' diagnoses. J Affect Disord. 2004;78(2):131-140.

55. Hansson M, Chotai J, Nordstöm A, Bodlund O. Comparison of two self-rating scales to detect depression: HADS and PHQ-9. $\mathrm{Br} \mathrm{J}$ Gen Pract. 2009;59(566):e283-e288.

56. Lotrakul M, Sumrithe S, Saipanish R. Reliability and validity of the Thai version of the PHQ-9. BMC Psychiatry. 2008;8:46.

57. Hyphantis T, Kotsis K, Voulgari PV, Tsifetaki N, Creed F, Drosos AA Diagnostic accuracy, internal consistency, and convergent validity of the Greek version of the patient health questionnaire 9 in diagnosing depression in rheumatologic disorders. Arthritis Care Res (Hoboken). 2011;63(9): 1313-1321.

58. Wang W, Bian Q, Zhao Y, et al. Reliability and validity of the Chinese version of the Patient Health Questionnaire (PHQ-9) in the general population. Gen Hosp Psychiatry. 2014;36(5):539-544.

59. Eysenck SBG, Eysenck HJ, Barrett P. A revised version of the psychoticism scale. Pers Individ Dif. 1985;6(1):21-29.
60. Qian M, Wu G, Zhu R, Zhang S. Development of the revised Eysenck Personality Questionnaire Short Scale for Chinese (EPQ-RSC). J Chin Psychol Acta Psychol Sin. 2000;32(3):317-323.

61. Naunnally JC, Bernstein IH. Psychometric Theory. 3rd ed. New York: McGraw-Hill; 1994.

62. Shrout PE, Fleiss JL. Intraclass correlations: uses in assessing rater reliability. Psychol Bull. 1979;86(2):420-428.

63. Kline RB. Principles and Practice of Structural Equation Modeling. New York: Guilford; 2005.

64. Ambrosio L, Portillo MC, Rodriguez-Blazquez C, et al. Satisfaction with Life Scale (SLS-6): First validation study in Parkinson's disease population. Parkinsonism Relat Disord. 2016;25:52-57.

65. Zwaanswijk W, Veen VC, Vedder P. The Youth Psychopathic Traits Inventory: A Bifactor Model, Dimensionality, and Measurement Invariance. Assessment. 2017;24(7):932-944.

66. Shrout PE. Measurement reliability and agreement in psychiatry. Stat Methods Med Res. 1998;7(3):301-317.

67. Spicer J. Making Sense of Multivariate Data Analysis. London: Sage; 2005.

68. Tabachnick BG, Fidell LS, Osterlind SJ. Using Multivariate Statistics 5th ed. New York: Allyn and Bacon; 2001.

69. Krakow B, Tandberg D, Scriggins L, Barey M. A controlled comparison of self-rated sleep complaints in acute and chronic nightmare sufferers. J Nerv Ment Dis. 1995;183(10):623-627.

70. American Academy of Sleep Medicine. International Classification of Sleep Disorders: Diagnostic and Coding Manual. 2nd ed. American Academy of Sleep Medicine; 2005.

71. DeVellis RF. Scale Development Theory and Applications. London: SAGE; 1991.

72. Simor P, Kovács I, Vargha A, Csóka S, Mangel B, Bódizs R. Nightmares, dream anxiety and psychopathology: the validation of the Hungarian version of the Van Anxiety Scale. Psychiatr Hung. 2009; 24(6):428-438. Hungarian.

73. Buysse DJ, Reynolds CF, Monk TH, Berman SR, Kupfer DJ. The Pittsburgh Sleep Quality Index: a new instrument for psychiatric practice and research. Psychiatry Res. 1989;28(2):193-213. 


\section{Supplementary materials}

Supplementary material S1 The Van Dream Anxiety Scale

The following questions relate to your dreams during the past month. These questions' aim is to examine how your dreams affect your life. Please indicate the most accurate answer for each question.

\begin{tabular}{|c|c|c|c|c|c|}
\hline Items & Never & Rarely & Sometimes & Usually & Often \\
\hline $\begin{array}{l}\text { I. How often have you had a frightening dream and awaken } \\
\text { completely from it? }\end{array}$ & I & 2 & 3 & 4 & 5 \\
\hline $\begin{array}{l}\text { 2. How often have you had difficulty in falling asleep after } \\
\text { awakening from a frightening dream? }\end{array}$ & I & 2 & 3 & 4 & 5 \\
\hline $\begin{array}{l}\text { 3. How often have you been afraid of sleeping because of your } \\
\text { frightening dreams? }\end{array}$ & I & 2 & 3 & 4 & 5 \\
\hline $\begin{array}{l}\text { 4. How often have you had trouble sleeping because of your } \\
\text { frightening dreams? }\end{array}$ & I & 2 & 3 & 4 & 5 \\
\hline \multicolumn{6}{|l|}{$\begin{array}{l}\text { 5. How often have you had the following symptoms because of } \\
\text { your frightening dreams? }\end{array}$} \\
\hline a. Shortness of breath & I & 2 & 3 & 4 & 5 \\
\hline b. Dizziness & I & 2 & 3 & 4 & 5 \\
\hline c. Exhaustion & I & 2 & 3 & 4 & 5 \\
\hline d. Palpitation & I & 2 & 3 & 4 & 5 \\
\hline e. Sweating & I & 2 & 3 & 4 & 5 \\
\hline f. Shivering & I & 2 & 3 & 4 & 5 \\
\hline g. Nausea & I & 2 & 3 & 4 & 5 \\
\hline h. Having stomach ache & I & 2 & 3 & 4 & 5 \\
\hline i. Tightness in chest & I & 2 & 3 & 4 & 5 \\
\hline j. Mouth dry & I & 2 & 3 & 4 & 5 \\
\hline k. Fear of death & I & 2 & 3 & 4 & 5 \\
\hline I. Sore throat & I & 2 & 3 & 4 & 5 \\
\hline $\begin{array}{l}\text { 6. How often could you recall in detail your frightening dreams } \\
\text { after awakening? }\end{array}$ & I & 2 & 3 & 4 & 5 \\
\hline 7. When have you usually gone to bed at night? & & & & & \\
\hline $\begin{array}{l}\text { 8. During the past month, how long (in minutes) has it usually } \\
\text { taken you to fall asleep each night? }\end{array}$ & & & & & \\
\hline $\begin{array}{l}\text { 9. During the past month, when have you usually gotten up in } \\
\text { the morning? }\end{array}$ & & & & & \\
\hline $\begin{array}{l}\text { 10. During the past month, how many hours of actual sleep did } \\
\text { you get at night? }\end{array}$ & & & & & \\
\hline $\begin{array}{l}\text { II. How often have you had felt yourself sleepy during the day } \\
\text { because of your frightening dreams? }\end{array}$ & I & 2 & 3 & 4 & 5 \\
\hline $\begin{array}{l}\text { 12. How often have you had felt yourself irritable or anxious in } \\
\text { the morning because of your frightening dreams? }\end{array}$ & I & 2 & 3 & 4 & 5 \\
\hline $\begin{array}{l}\text { 13. How often have you had difficulties with your occupational } \\
\text { functioning or normal routines because of your frightening } \\
\text { dreams? }\end{array}$ & I & 2 & 3 & 4 & 5 \\
\hline $\begin{array}{l}\text { 14. How often have you had difficulties with your usual familial } \\
\text { relationships because of your frightening dreams? }\end{array}$ & I & 2 & 3 & 4 & 5 \\
\hline $\begin{array}{l}\text { 15. How often have you had difficulties with your usual social } \\
\text { activities or relationships with because of your frightening } \\
\text { dreams? }\end{array}$ & I & 2 & 3 & 4 & 5 \\
\hline $\begin{array}{l}\text { 16. How often have you had disturbances with your mood or } \\
\text { psychological status because of your frightening dreams? }\end{array}$ & I & 2 & 3 & 4 & 5 \\
\hline $\begin{array}{l}\text { 17. How often have you had memory/concentration problems } \\
\text { or difficulties because of your frightening dreams? }\end{array}$ & I & 2 & 3 & 4 & 5 \\
\hline
\end{tabular}


梦的焦虑量表

以下是一些有关你过去1个月的梦相关的问题。这些问题旨在检验梦如何影响你的生活。请为每个问题指出最确切的回答。

\begin{tabular}{|c|c|c|c|c|c|}
\hline 条目 & 从来没有 & 很少 & 有时 & 经常 & 总是 \\
\hline I. 做可怕的梦并彻底被惊醒 & I & 2 & 3 & 4 & 5 \\
\hline 2. 在可怕的梦后难以再次入睡 & I & 2 & 3 & 4 & 5 \\
\hline 3. 因为可怕的梦而害怕入睡 & I & 2 & 3 & 4 & 5 \\
\hline 4. 因为可怕的梦而睡不好觉 & I & 2 & 3 & 4 & 5 \\
\hline \multicolumn{6}{|l|}{ 5. 因为可怕的梦而出现下列症状 } \\
\hline a. 呼吸急促 & I & 2 & 3 & 4 & 5 \\
\hline b. 头晕 & I & 2 & 3 & 4 & 5 \\
\hline c. 精疲力竭 & I & 2 & 3 & 4 & 5 \\
\hline d. 心悸 & I & 2 & 3 & 4 & 5 \\
\hline e. 出汗 & I & 2 & 3 & 4 & 5 \\
\hline f. 发抖 & I & 2 & 3 & 4 & 5 \\
\hline g. 恶心 & I & 2 & 3 & 4 & 5 \\
\hline h. 出现腹痛 & I & 2 & 3 & 4 & 5 \\
\hline i. 胸闷 & I & 2 & 3 & 4 & 5 \\
\hline j. ロ干 & I & 2 & 3 & 4 & 5 \\
\hline k. 害怕死亡 & I & 2 & 3 & 4 & 5 \\
\hline I. 咽喉痛 & I & 2 & 3 & 4 & 5 \\
\hline 6. 醒来后详细地回忆起可怕的梦 & I & 2 & 3 & 4 & 5 \\
\hline 7. 近1个月, 晚上上床睡觉通常是_ & & & & & \\
\hline 8. 近1个月, 从上床到入睡通常需要 & & & & & \\
\hline 9. 近1个月, 早上通常起床时间_—点钟 & & & & & \\
\hline 10. 近1个月, 每夜通常实际睡眠时间_小时 & & & & & \\
\hline II. 因为可怕的梦而白天犯困 & I & 2 & 3 & 4 & 5 \\
\hline 12. 因为可怕的梦而在早晨感到烦躁或焦虑 & I & 2 & 3 & 4 & 5 \\
\hline 13. 因为可怕的梦而在职业功能/机能或日常生活中遇到困难 & I & 2 & 3 & 4 & 5 \\
\hline |4. 因为可怕的梦而在日常家庭关系中遇到困难 & I & 2 & 3 & 4 & 5 \\
\hline 15. 因为可怕的梦而在社交活动或人际关系中遇到困难 & I & 2 & 3 & 4 & 5 \\
\hline 16. 因为可怕的梦而对扰乱了自己的情绪或心理状态 & I & 2 & 3 & 4 & 5 \\
\hline 17. 因为可怕的梦而出现记忆/注意力上的问题或困难 & I & 2 & 3 & 4 & 5 \\
\hline
\end{tabular}

Note: Copyright: Ağargün MY, Kara H, Bilici M, et al. The Van Dream Anxiety Scale: A Subjective Measure of Dream Anxiety in Nightmare Sufferers. Sleep and Hypnosis. 1999; I(4).'

\section{Reference}

1. Ağargün MY, Kara H, Bilici M, et al. The Van Dream Anxiety Scale: A Subjective Measure of Dream Anxiety in Nightmare Sufferers. Sleep and Hypnosis. 1999;1(4).

\section{Publish your work in this journal}

Neuropsychiatric Disease and Treatment is an international, peerreviewed journal of clinical therapeutics and pharmacology focusing on concise rapid reporting of clinical or pre-clinical studies on a range of neuropsychiatric and neurological disorders. This journa is indexed on PubMed Central, the 'PsycINFO' database and CAS, and is the official journal of The International Neuropsychiatric Association (INA). The manuscript management system is completely online and includes a very quick and fair peer-review system, which is all easy to use. Visit http://www.dovepress.com/testimonials.php to read real quotes from published authors. 